Copyright (C) 2020 University of Bucharest Printed in Romania. All rights reserved

ISSN print: $1224-5984$

ISSN online: 2248-3942
Rom Biotechnol Lett. 2020; 25(2): 1456-1464

doi: $10.25083 / \mathrm{rbl} / 25.2 / 1456.1464$

Received for publication, July, 13, 2018

Accepted, August, 6, 2018

Original paper

\title{
Biochemical markers of inflammatory syndrome in chronic rhinosinusitis
}

\author{
ALINA GABRIELA DUŢU ${ }^{1}$, DIANA VLAD ${ }^{2}$, CRISTINA DRUGAN ${ }^{*}$, ALEXANDRA \\ M. CRĂCIUN ${ }^{1}$, TUDOR C. DRUGAN ${ }^{3}$, FLAVIU TABARAN ${ }^{4}$, SILVIU ALBU $^{2}$
}

\footnotetext{
${ }^{1}$ Department of Medical Biochemistry, "Iuliu Haţieganu" University of Medicine and Pharmacy Cluj-Napoca, Cluj-Napoca, Romania

${ }^{2} 2$ nd Department of Otolaryngology, "Iuliu Haţieganu" University of Medicine and Pharmacy Cluj-Napoca, Cluj-Napoca, Romania

${ }^{3}$ Department of Medical Informatics and Biostatistics, "Iuliu Haţieganu” University of Medicine and Pharmacy Cluj-Napoca, Cluj-Napoca, Romania

${ }^{4}$ Department of Anatomic Pathology, University of Agricultural Sciences and Veterinary Medicine, Cluj-Napoca, Romania
}

\begin{abstract}
Chronic rhinosinusitis (CRS), defined as a persistent inflammation of the nasal and sinus mucosa, affects approximately $10 \%$ of the European adult population. Our study focused on the evaluation of serum chitotriosidase (Cht) and 25-hydroxyvitamin $\mathrm{D}_{3}$ (25-OH-D3) as potential biomarkers of CRS-associated inflammation. This cross-sectional, randomized, case-control study included 16 CRS patients and 21 non-smoking controls, investigated for nasal septum deviation. No inflammatory conditions were diagnosed in both investigated groups and no anti-inflammatory treatments were administered for at least 3 weeks prior to serum sampling. Serum Cht activity was significantly increased in CRS patients, compared to the controls (Mann-Whitney U test $\mathrm{p}=0.030$ ), while $25-\mathrm{OH}-\mathrm{D} 3$ levels were significantly decreased in patients, versus controls (Mann-Whitney $U$ test $\mathrm{p}=0.001$ ). No significant Cht or 25-OH-D3 variations were induced by any of the investigated covariates, such as the coexistence of comorbidities, microbial biofilms or previous corticosteroid treatments. Receiver operating characteristic (ROC) analysis indicated a good discriminating capacity between patients and controls, for both Cht and 25-OH-D3, suggesting their possible utility as non-invasive biomarkers in CRS. Patients with polyps exhibited lower 25-OH-D3 levels, while those with microbial biofilms had higher Cht and lower 25-OH-D3 values than their counterparts, suggesting that biofilms may be an aggravating factor in disease pathogenesis.
\end{abstract}

Keywords Chronic rhinosinusitis, biomarkers, inflammation, chitotriosidase, vitamin D.

To cite this article: DUŢU AG, VLAD D, DRUGAN C, CRĂCIUN AM, DRUGAN TC, TABARAN F, ALBU S. Biochemical markers of inflammatory syndrome in chronic rhinosinusitis. Rom Biotechnol Lett. 2020; 25(2): 1456-1464. DOI: 10.25083/rb1/25.2/1456.1464

*Corresponding author: CRISTINA DRUGAN, Department of Medical Biochemistry, "Iuliu Haţieganu" University of Medicine and Pharmacy Cluj-Napoca, Cluj-Napoca, Romania

E-mail: cdrugan@ umfcluj.ro 


\section{Introduction}

Chronic rhinosinusitis (CRS) is a frequent pathological condition exhibiting a strong social impact, in terms of reducing the quality of life and increasing the cost of health care. CRS affects approximately $10 \%$ of the European adult population and it is defined as a persistent inflammation of the nasal and sinus mucosa, with a length of at least 12 weeks (FOKKENS \& al [1]). Based on the potential existence of nasal polyps, CRS is divided into two large subtypes: with nasal polyps (CRSwNP) and without nasal polyps (CRSsNP). The two categories are further differentiated by the type of inflammation and of tissue remodelling (VAN CROMBRUGGEN \& al [2]; VAN BRUAENE \& al [3]). CRSsNP is characterised by a predominantly neutrophilic inflammatory infiltrate, associated with Th1 lymphocytes (VAN CROMBRUGGEN \& al [2]; VAN ZELE \& al [4]). Instead, the eosinophilic infiltrate and tissue remodelling based on fibroblast proliferation, with a $\mathrm{Th} 1 / \mathrm{Th} 2$ ratio in favour of $\mathrm{Th} 2$ cells, are the main features of CRSwNP (VAN CROMBRUGGEN \& al [2]; VAN ZELE \& al [4]).

The pathogenesis of CRS has been widely studied. However, it is still not fully understood, due to the complexity of host-environment interactions. Microbial elements, such as superantigens, fungal infections or bacterial biofilms, have been described as pathogenic factors (FOKKENS \& al [1]; BACHERT \& al [5]). Among these, bacterial biofilms are frequently involved, especially in the refractory CRS (FOKKENS \& al [1]; HARVEY \& al [6]). This threedimensional structure consists of bacterial cell aggregates incorporated into an auto-secreted exopolysaccharide matrix, attached to either living, or inert surfaces (HARVEY \& al [6]). Within the biofilm, bacterial cells have a slower metabolic rate, the exopolysaccharide matrix providing protection against the phagocytic action of macrophages, as well as resistance to antibiotics (SINGH \& al [7]; DLUGASZEWSKA \& al [8]; GEORGESCU \& al [9]).

In the CRS-associated inflammatory process, macrophages are activated by either $\mathrm{T}$ cell mediators (such as interferon gamma or RANTES), or by bacterial pathogenicity factors (LEE \& LANE [10]).

Chitotriosidase (Cht) is a hydrolytic enzyme secreted by activated macrophages, acting on both chitin and chitin-like substrates. Initially, high levels of circulating Cht have been reported in Gaucher disease and other lysosomal storage disorders, however, recent studies have demonstrated elevated enzymatic activities in other diseases, such as diabetes mellitus, atherosclerosis, pulmonary disorders, parasitic and helminthic infections (MALAGUARNERA [11]; ELMONEM \& al [12]; MUSUMECI [13]). As a product of non-specific macrophage activation, Cht may be considered a biomarker of systemic inflammation (MUSUMECI [13]; CIOCAN $\&$ al [14]).
Besides its well-known roles on phospho-calcium metabolism, vitamin D3 (VD3), the precursor of the steroid hormone calcitriol, acts as an immunomodulator, with antiinflammatory and antiproliferative effects. (AKBAR \& ZACHAREK [15]; KAMEN \& TANGPRICHA [16]). Its dietary precursor, the cholecalciferol, synthesized in the skin following UV exposure, undergoes liver hydroxylation to 25-hydroxy-vitamin D3 (25-OH-D3), which is the storage form of the vitamin and will be released into circulation for peripheral tissue uptake. Its renal conversion to active calcitriol is catalysed by 1 -alpha-hydroxylase (GALLIENI \& al [17]). VD3 receptors have been found in T-lymphocytes, macrophages and fibroblasts (De LUCA \& CANTORNA [18]).

The investigation of CRS-associated inflammatory syndrome could lead to a better understanding of the pathogenesis of this disease and to an improvement in patient care. In this context, we sought to evaluate the inflammatory syndrome, by means of biochemical markers reflecting its extent. Thus, we assessed serum Cht activity and 25-OH-D3 levels in CRS patients and analysed their variations as a function of disease subtype and bacterial biofilm presence.

\section{Materials and Methods}

The study was approved by the ethic committee of our University (no.273/16.06.2016) and was conducted within a year, between June 2016 and June 2017, at the Clinical Hospital CF from Cluj-Napoca. All patients and controls involved have agreed to sign the informed consent.

We conducted a cross-sectional, randomized, casecontrol study. Sixteen patients with CRS were included in the case group. The control group comprised 21 nonsmoking subjects investigated for nasal septum deviation, without other known associated pathology. CRS diagnosis was based on disease history, cranial computer tomography (CT) imaging and nasal endoscopy examination. Other inclusion criteria for the case group were the absence of the known inflammatory disease and previously inefficient CRS drug treatment. Exclusion criteria for both patient and control groups were the following: age under 18, immunocompromised patients, administration of vitamin D supplements, antibiotic or corticosteroid treatment until at least 3 weeks prior to hospital admission.

Under endoscopic control, fragments of inflamed sinus mucosa from the middle meatus and the ethmoidal sinus were sampled from each CRS patient and stained with Haematoxylin-Eosin (H-E) and Gram colorations, for confirmation of the bacterial colonisation. Biofilms were detected by Toluidine Blue identification of the bacterial polysaccharide layers, characteristic for the Gram-positive or Gram-negative micro-colonies. The presence of neutrophils, eosinophils, plasma cells and lymphocytes in the cellular infiltrate was revealed by $\mathrm{H}-\mathrm{E}$ staining.

Immediately after harvest, nasal biopsy tissues were immersed for fixation in $10 \%$ neutral-buffered formalin 
(NBF), for 48-72 hours. After transverse trimming, samples were dehydrated with an ethylic alcohol gradient $(70 \%$, $80 \%, 95 \%$ and $100 \%$ ), clarified in xylene and embedded in paraffin wax. Multiple sections were cut from each paraffin block at $4 \mu \mathrm{m}$ thickness and routinely stained with H-E. The stained histological slides were examined with an Olympus BX41 microscope. Images were obtained with an Olympus UC30 digital camera and processed by the Olympus Stream Image Analysis Software (Olympus Corporation, Tokyo, Japan) (HOCHSTIM \& al [19]; SRIDHARAN \& al [20]).

Serum samples obtained from freshly drawn blood were immediately stored at $-20^{\circ} \mathrm{C}$. Chitotriosidase activity was measured using a fluorescent artificial substrate, as previously described (HOLLAK \& al [21]). One patient and two controls with undetectable chitotriosidase activity, probably because of the homozygosity for a null allele (BOOT \& al [22]), were excluded from the analysis of enzymatic activity results.

Serum 25-OH-D3 levels were measured using an enzyme-linked immunosorbent assay (ELISA) according to the instructions of the manufacturer (DiaMetra S.r.l., Italy). For this assay, insufficiency was defined as a level below $30 \mathrm{ng} / \mathrm{mL}$ and deficiency as a concentration below $10 \mathrm{ng} / \mathrm{mL}$.

Statistical analyses were performed with the IBM SPSS software version 25.0 (IBM, USA). Using the
Shapiro-Wilk test we found that the quantitative variables had no normal distributions and therefore group comparisons were performed with the Mann-Whitney U test. Data were presented as median and interquartile range (IQR). $P$ values less than 0.05 were considered significant.

\section{Results}

\section{Patient characteristics}

The studied sample comprised 16 CRS patients aged between 18 and 80 years, included in the CRSwNP (68.75\%) and CRSsNP $(31.25 \%)$ subtypes, respectively. $75 \%$ of them came from urban areas and $25 \%$ declared a rural origin. The control group consisted of 21 non-smoking patients with nasal septum deviation and no past or present diagnosis of an acute or chronic inflammatory condition.

Based on clinical records and interview-based information respectively, $37.50 \%$ of CRS patients had been diagnosed with bronchial asthma (BA), and $31.25 \%$ declared themselves affected by various allergies. All the patients with known allergies presented BA as well and had been treated with nasal corticosteroids. All the patients with BA belonged to the CRSwNP category.

Bacterial biofilms were detected by H-E (Figure 1) and by Toluidine Blue (Figure 2) staining in $56.25 \%$ of CRS patients, without statistically significant differences between CRSwNP and CRSsNP subgroups, respectively.

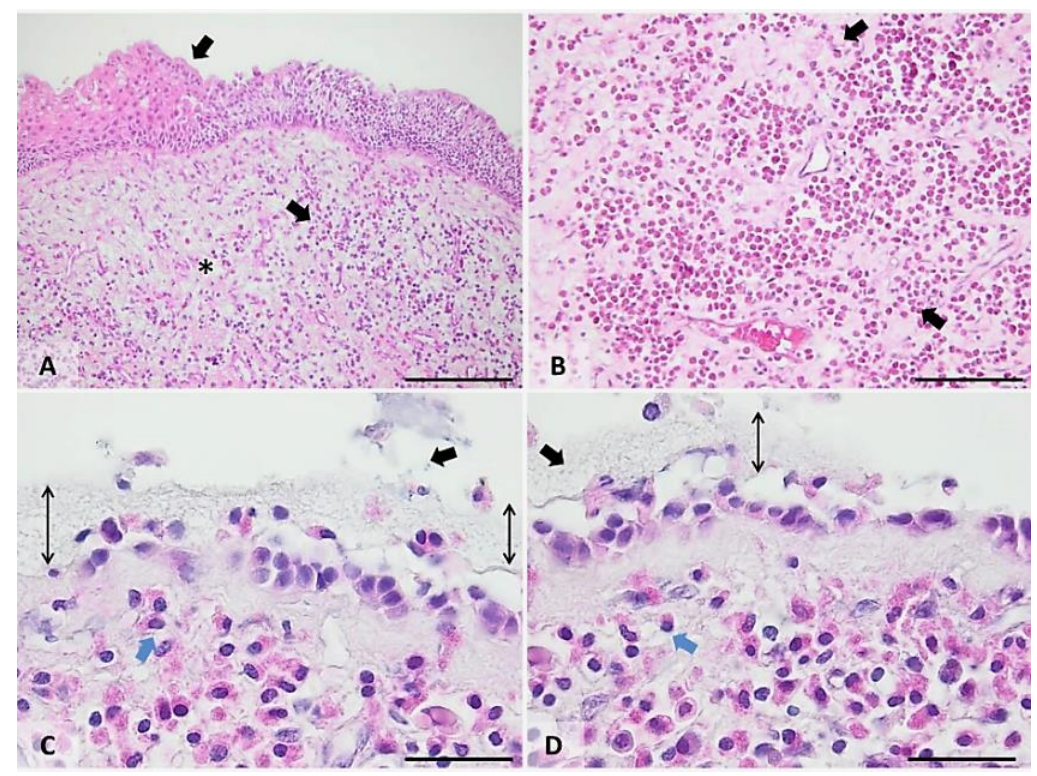

Figure 1. Histopathological aspect of nasal mucosa (Haematoxylin-Eosin staining): presence of biofilms, abundant inflammatory infiltrate with eosinophils, lymphocytes and plasma cells. A. nasal mucosa with squamous metaplasia (upper arrow), diffuse leucocyte infiltrate (lower arrow) and oedema (asterisk); 4x, scale $=1000 \mu \mathrm{m}$;

B. detail of the lamina propria, characterised by massive eosinophilic infiltrate (indicated by arrows); 20x, scale $=200 \mu \mathrm{m}$;

C and D. superficial nasal mucosa with epithelial desquamation, atrophy and superficial mucoid material, characteristic for the microbial biofilms (reticulate aspect with coccoid bacteria indicated by short arrows, thickness indicated by double arrows); 100x, scale $=40 \mu \mathrm{m}$. 


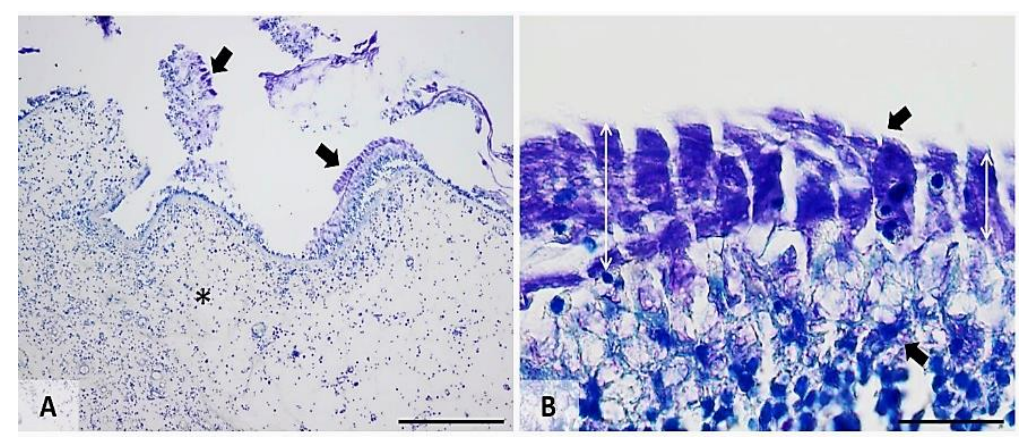

Figure 2. Histopathological aspect of nasal mucosa (Toluidine Blue staining). $\mathbf{A}$ and B. polysaccharide rich material intensely positive with Toluidine Blue, associated with bacterial biofilms; 4x, scale $=1000 \mu \mathrm{m}$ (image A) and 100x, scale $=40 \mu \mathrm{m}$ (image B).

\section{Serum chitotriosidase activity and 25-hydroxy- vitamin D3 levels}

Serum Cht enzymatic activity and 25-OH-D3 concentrations did not follow a normal distribution: using the Shapiro-Wilk test, we obtained $\mathrm{p}=0.020$ and $\mathrm{p}<0.001$ for Cht activity and for 25-OH-D3 levels, respectively.

For the controls, the enzymatic activities of $\mathrm{Cht}$ and the concentrations of 25-OH-D3 were within the reference ranges. However, in CRS patients, the distribution of Cht activity values was significantly different from that of the control group (Mann-Whitney U test $\mathrm{p}=0.030$ ) (Table 1, Figure 3). Likewise, statistically significant differences in the distribution of 25-OH-D3 values between patients and controls have been found (Mann-Whitney U test $\mathrm{p}=0.001$ ). These differences are highlighted in Table 1 and illustrated in Figure 3.

Table 1. Results of chitotriosidase activity and 25-hydroxy-vitamin D3 serum level assays

\begin{tabular}{|c|c|c|c|c|}
\hline \multirow[t]{2}{*}{ Group } & \multicolumn{2}{|c|}{$\begin{array}{l}\text { Chitotriosidase activity } \\
(\mathrm{nmol} / \mathrm{mL} / \mathrm{h})\end{array}$} & \multicolumn{2}{|c|}{$\begin{array}{c}\text { 25-hydroxy-vitamin D3 } \\
\text { (ng/mL) }\end{array}$} \\
\hline & Median & IQR & Median & IQR \\
\hline CRS patients & $230.00 * *$ & $150.00-280.00$ & $22.70 * *$ & $16.70-28.30$ \\
\hline Controls & $130.00 * *$ & $100.00-180.00$ & 43.50 ** & $32.20-64.20$ \\
\hline Patient origin* & Median & IQR & Median & IQR \\
\hline Rural & 145.00 & $100.00-310.00$ & 37.10 & $27.50-73.30$ \\
\hline Urban & 160.00 & $130.00-250.00$ & 28.10 & $23.80-32.20$ \\
\hline Nasal polyps* & Median & IQR & Median & IQR \\
\hline Present & 150.00 & $120.00-300.00$ & 27.35 & $22.70-32.20$ \\
\hline Absent & 150.00 & $130.00-250.00$ & 37.10 & $27.90-64.20$ \\
\hline Bronchial asthma* & Median & IQR & Median & IQR \\
\hline Present & 140.00 & $120.00-300.00$ & 27.50 & $23.80-45.60$ \\
\hline Absent & 160.00 & $130.00-250.00$ & 32.20 & $27.90-45.70$ \\
\hline Bacterial biofilm* & Median & IQR & Median & IQR \\
\hline Present & 260.00 & $140.00-300.00$ & 23.45 & $14.40-29.30$ \\
\hline Absent & 140.00 & $120.00-180.00$ & 32.20 & $27.90-45.60$ \\
\hline
\end{tabular}

\section{Impact of covariates on chitotriosidase and 25-hydroxy-vitamin D3 values}

The analysis of serum Cht activities indicated no statistically significant differences between CRSwNP and CRSsNP subgroups (Mann-Whitney U test $\mathrm{p}=0.694$ ). Cht activity variations displayed no statistically significant differences with respect to the patient origin (Mann-Whitney
$\mathrm{U}$ test $\mathrm{p}=0.955$ ) or previous corticosteroid treatment (Mann-Whitney U test $\mathrm{p}=0.074$ ). Similarly, we checked the potential dependence of Cht values on the association between CRS and BA (Mann-Whitney U test $\mathrm{p}=0.745$ ) and on the presence of bacterial biofilms (Mann-Whitney $\mathrm{U}$ test $\mathrm{p}=0.070$ ), without revealing statistically significant differences. 



Figure 3. Significant differences observed for the distribution of serum chitotriosidase activities $(\mathrm{nmol} / \mathrm{mL} / \mathrm{h})$ and 25-hydroxy-vitamin D3 concentrations $(\mathrm{ng} / \mathrm{mL})$ in chronic rhinosinusitis patients versus controls.

A similar behaviour was observed for the variation of serum 25-OH-D3 levels. Thus, neither polyposis, nor previous corticosteroid treatment did not induce significant differences in its values (Mann-Whitney $U$ test $p=0.236$ and $\mathrm{p}=0.175$, respectively. Likewise, the origin of patients had no significant impact on the variation of this parameter (Mann-Whitney U test $\mathrm{p}=0.358$ ). Moreover, serum 25-OH-D3 values were not significantly influenced by the association between CRS and BA (Mann-Whitney U test $\mathrm{p}=0.603$ ) or between CRS and bacterial biofilms (MannWhitney U test $\mathrm{p}=0.054$ ).

Although the presence of microbial biofilms did not induce statistically significant differences in Cht activity levels, we recorded higher enzymatic activities in patients with biofilms than in other CRS patients (median and IQR were 260 (140-300) versus $140(120-80) \mathrm{nmol} / \mathrm{mL} / \mathrm{h}$, respectively). We also noticed that $25-\mathrm{OH}-\mathrm{D} 3$ concentrations were lower in patients with biofilms, compared to those without this feature (median and IQR were
23.45 (14.40-29.30) versus $32.20(27.90-45.60) \mathrm{ng} / \mathrm{mL}$, respectively). Similarly, 25-OH-D3 values were lower in patients with polyps, again without reaching statistical significance (Table 1).

\section{Discriminative capacity of chitotriosidase and 25-hydroxy-vitamin D3}

As both investigated parameters (Cht and 25-OH-D3) were not influenced by comorbidities, microbial biofilms, previous therapies or the origin of patients, we considered their evaluation as diagnostic tests for CRS and verified their ability to effectively discriminate between patients and controls, using the receiver operating characteristic (ROC) curve (Table 2, Figure 4).

The area under the ROC curve approaches 0.80 for Cht activity and exceeds this value for the concentration of 25-OH-D3, indicating a good discrimination between patients and controls and suggesting their potential utility as biomarkers of systemic inflammation in CRS.
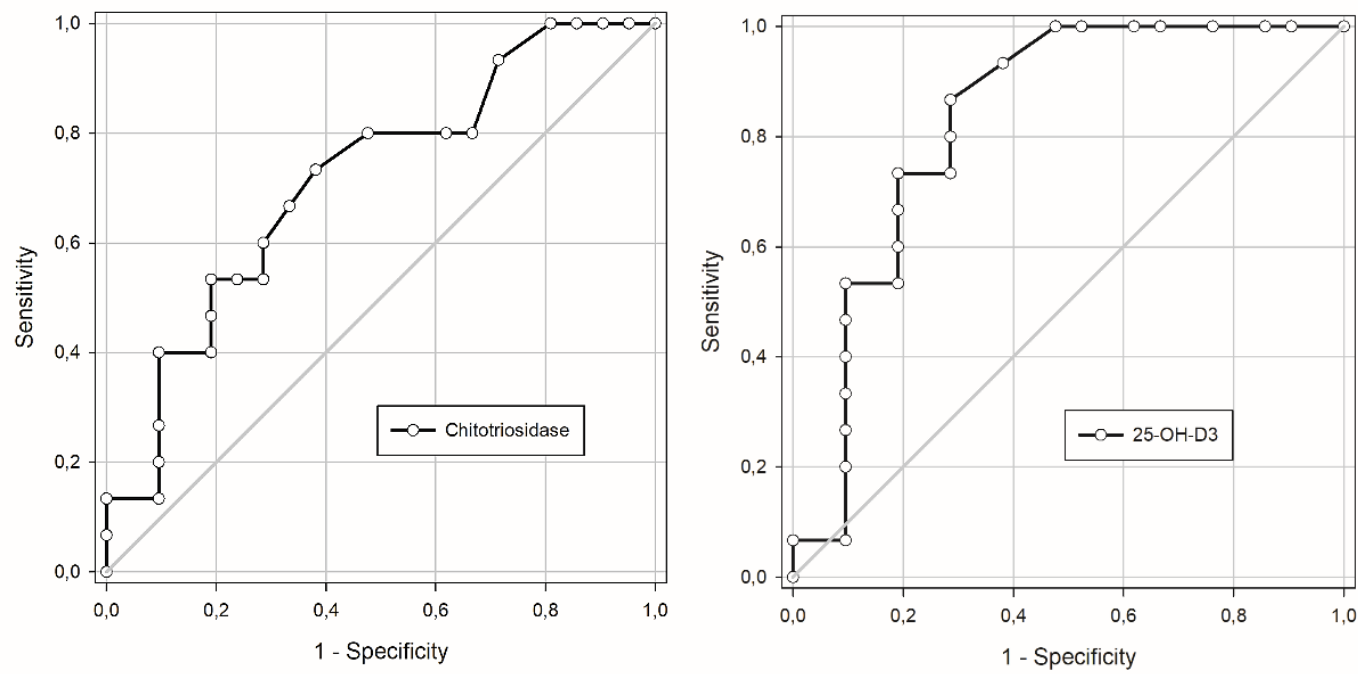

Figure 4. Receiver operating characteristic curve for the evaluation of the discriminative capacity of chitotriosidase (left) and 25-hydroxy-vitamin D3 (right) as biomarkers of chronic rhinosinusitis. 
Table 2. Parameters of receiver operating characteristic curves for chitotriosidase and 25-hydroxy-vitamin D3 as biomarkers in the diagnosis of chronic rhinosinusitis

\begin{tabular}{|l|l|l|}
\hline \multicolumn{1}{|c|}{ Parameter } & \multicolumn{1}{|c|}{$\begin{array}{c}\text { Chitotriosidase activity } \\
(\mathrm{nmol} / \mathrm{mL} / \mathrm{h})\end{array}$} & \multicolumn{1}{|c|}{$\begin{array}{c}\text { 25-hydroxy-vitamin D3 } \\
(\mathrm{ng} / \mathrm{mL})\end{array}$} \\
\hline $\begin{array}{l}\text { ROC curve area } \\
\text { [confidence interval] }\end{array}$ & $0.7143[0.5436-0.8850]$ & $0.8286[0.6912-0.9660]$ \\
\hline p value & 0.0303 & 0.008 \\
\hline
\end{tabular}

\section{Discussions}

Given that CRS affects patients' quality of life to a similar extent as heart failure, angina, chronic obstructive pulmonary disease and back pain (GLIKLICH \& METSON [23]) and increases health care costs by the numerous medical appointments, often followed by sick leave days, it is of great interest to evaluate biomarkers that might optimise the monitoring of disease progression and, implicitly, the treatment effectiveness. As CRS is a multifactorial pathology, the inflammatory response is mediated by a large number of biological messengers, acting on different signalling pathways; therefore, one cannot delineate a single mediator, playing a key role in the disease progression and in the pathophysiology (KATO [24]).

In CRS, a persistent inflammatory syndrome was frequently found in association with microbial biofilms (HARVEY \& al [6]). Although this association is well documented (HOCHSTIM \& al [25]; JUNG \& al [26]), the involvement of bacterial biofilms in CRS physiopathology is still being extensively investigated. In this study, we have identified the presence of biofilms in $56.25 \%$ of patients with CRS, which is consistent with literature data, showing variable biofilm results (from $28 \%$ to over $70 \%$ of the investigated patients) (DLUGASZEWSKA \& al [8]; HEKIERT \& al [27]; WANG \& al [28]). Most studies have shown that biofilms may be an aggravating factor of disease progression, being associated with a refractory evolution to the usual therapeutic measures (LEE \& LANE [10]; TROMBITAS \& al [29]; SINGHAL \& al [30]).

In our study, we evaluated serum Cht activity in CRS patients, compared to the control group. The enzymatic activity of Cht was significantly higher in patients than in controls, indicating the activation of tissue macrophages and, consequently, the existence of an important inflammatory syndrome. As none of the covariates considered in this study have had a significant impact on circulating chitotriosidase, we assume that this inflammatory syndrome is most likely an intrinsic element of the pathogenesis and evolution of CRS.

Therefore, we verified the ability of this enzyme to accurately discriminate between patients and controls, in order to evaluate its utility as a CRS biomarker. Based on the results of ROC curve analysis, we believe that circulating Cht may be considered as a non-invasive biomarker of CRS-induced inflammation and it may also be used for patient monitoring and follow-up. To the best of our knowledge, this is the first study that addresses the usefulness of Cht as a biomarker of this disease. Besides its discriminative capacity between CRS patients and controls, the high sensitivity of this enzyme to changes in activated macrophage numbers may indicate its possible use for the monitoring of disease-associated inflammatory syndrome (VAN DUSSEN \& al [31]).

Previous attempts to evaluate the chitinolytic activity of Cht in nasal polyps, by gene expression studies and enzymatic activity assays in bioptic fragments from polyps and the inferior turbinate tissue, revealed a significant increase of the enzyme levels in CRSwNP patients, compared with controls (PARK \& al [32]; PARK \& al [33]). We have also noticed that biofilm-positive patients displayed higher circulating Cht values than other CRS patients, although our results did not reach statistical significance. However, we may speculate that the presence of biofilms could induce a more pronounced inflammation, responsible for the higher Cht values in these patients. This hypothesis could be confirmed by further studies performed on larger numbers of patients, sequentially followed over longer lengths of time.

Another study has shown that the significantly elevated Cht activity in nasal polyps was associated with allergic rhinitis and smoking (HEO \& al [34]). In our study, no significant differences have been found between Cht activities in patients with bronchial asthma, compared to other CRS patients, since all our allergic subjects also had bronchial asthma and nasal polyps.

A second line of investigation of the inflammatory response in CRS patients was the evaluation of the status of VD3, reflected by the serum levels of 25-OH-D3. As expected, serum 25-OH-D3 levels were significantly lower in CRS patients than in the control group, this result being consistent with literature data (ABUZEID \& al [35]; STOKES \& RIMMER [36]). Indeed, previous studies investigated the effect of 25-OH-D3 variation on systemic inflammation, by the evaluation of inflammatory markers and found that lower VD3 levels were correlated with a significant increase in the number of dendritic cells CD209+ and of dendritic cell regulatory products, such as prostaglandin E2 and granulocyte-macrophage colonystimulating factor (MULLIGAN \& al [37]). 
No statistically significant differences were noted between CRSwNP and CRSsNP subgroups, although mean 25-OH-D3 values were lower in patients with polyps than among those without polyps and, of course, than in the control group. This result is also in agreement with the literature data, which showed significantly lower values in patients with polyps, compared to those without polyps and to the control group, regardless of age, sex, smoking or atopic status (MULLIGAN \& al [37]; MULLIGAN \& al [38]; MULLIGAN \& al [39]; SCHLOSSER \& al [40]). In our study, the lack of a statistical significance of this result is most likely due to the limited number of patients in each investigated subgroup.

Recent studies have pointed out to the relationship between the decreased serum 25-OH-D3 levels and a more severe clinical picture of CRS (MULLIGAN \& al [38]; WANG \& al [41]). In CRSwNP patients, a decrease of 1-alpha-hydroxylase activity has been observed, a finding that may explain the decreased calcitriol level in the sinonasal epithelium, correlated with excessive fibroblast proliferation in nasal polyps (MULLIGAN \& al [38]; CAROLL \& al [42]). Since calcitriol is a potent inhibitor of pro-inflammatory cytokine synthesis (such as RANTES and interleukins 6 and 8), its reduced concentration may contribute to the more severe clinical manifestations in CRSwNP patients (CAROLL \& al [42]; ROSTKOWSKANADOLSKA \& al [43]).

Furthermore, the administration of VD3 seems to enhance the effect of corticosteroid therapy in CRS. In cell cultures, topical VD3 analogues (calcitriol and tacalcitriol) have been shown to potentiate the effects of Budesonide application on the suppression of polyp fibroblast proliferation (ROSTKOWSKA-NADOLSKA \& al [43]; ROSTKOWSKA-NADOLSKA \& al [44]).

Although in our study mean serum 25-OH-D3 levels displayed no statistically significant differences between CRS subgroups with and without microbial biofilms, this metabolite was still lower in patients with biofilms, than among other patients. This result is consistent with the literature data, indicating that the antibacterial effect of VD3 can be explained by its ability to stimulate the synthesis of mediators belonging to the cathelicidin family. In particular, LL-37, an antimicrobial peptide from the human cathelicidin family, has demonstrated a strong inhibitory effect on bacterial biofilm formation (SULTAN \& al [45]; PARK \& al [46]).

In our patients, circulating 25-OH-D3 levels were not significantly affected by any of the investigated covariates. Therefore, we checked the ability of this metabolite to correctly differentiate between patients and controls, in order to evaluate its usefulness as a biochemical marker of CRS. Based on the results of the ROC curve analysis, we may consider that circulating 25-OH-D3 could be included among the biomarkers of CRS associated inflammation. In this respect, our study is the first to evaluate the possibility of using this VD3 metabolite as a non-invasive biomarker, equally useful for the accurate differentiation between CRS patients and controls and also, in the long term, for the monitoring of disease progression.

The main drawback of this study is related to the limited number of the investigated patients, which may explain the absence of statistically significant correlations between patient subgroups and the investigated parameters. However, these data represent preliminary results that can pave the way for new therapeutic and monitoring opportunities in CRS.

In this respect, an interesting research direction could focus on the dynamic evaluation of the proposed biomarkers, both before and after surgical intervention. Furthermore, the investigation of these parameters among patient subgroups could highlight specific outcomes that may be important for individualised therapy and clinical follow-up.

Although this study is a preliminary one, based on the investigation of a small number of patients, our results indicate that the evaluation of inflammatory biomarkers, such as circulating chitotriosidase and 25-OH-D3 could highlight interesting aspects of CRS pathogenesis and progression. In particular, the chitinolytic activity of Cht deserves further investigation as a potential defence mechanism against the development of bacterial biofilms. In addition, since these biofilms are often associated with refractory CRS, vitamin D adjuvant supplementation may improve the effectiveness of the therapy. Further studies, conducted on larger patient cohorts, monitored over a longer time frame, are nonetheless necessary to confirm these hypotheses.

\section{Conclusion}

Both Cht and 25-OH-D3 could be considered as noninvasive biomarkers, whose utility in the follow-up of CRSassociated inflammation requires further investigation. Patients with polyps exhibited lower 25-OH-D3 values, compared to those without polyps, while patients with microbial biofilms had higher mean values of chitotriosidase and a lower mean value of 25-OH-D3 than their counterparts, a finding which may reveal the importance of microbial biofilms as an aggravating factor of the disease pathogenesis.

\section{Conflict of interest}

The authors declare no conflict of interest related to the present study. 


\section{References}

1. WJ FOKKENS, VJ LUND, J MULLOL, C BACHERT, I ALOBID, F BAROODY, et al. European position paper on rhinosinusitis and nasal polyps 2012. Rhinol Suppl. 23:1-298 (2012).

2. K VAN CROMBRUGGEN, N ZHANG, P GEVAERT, $P$ TOMASSEN, C BACHERT. Pathogenesis of chronic rhinosinusitis: Inflammation. The Journal of allergy and clinical immunology. 128 (4): 728-732 (2011).

3. N VAN BRUAENE, C BACHERT. Tissue remodelling in chronic rhinosinusitis. Curr Opin Allergy Clin Immunol. 11(1):8-11 (2011).

4. T VAN ZELE, S CLAEYS, P GEVAERT, G VAN MAELE, G HOLTAPPELS, P VAN CAUWENBERGE, et al. Differentiation of chronic sinus diseases by measurement of inflammatory mediators. Allergy. 61(11):12801289 (2006).

5. C BACHERT et al. ICON: chronic rhinosinusitis. World Allergy Organization Journal. 7:25 (2014).

6. RJ HARVEY, VJ LUND. Biofilms and chronic rhinosinusitis: systematic review of evidence, current concepts and directions for research. Rhinology. 45, 3-13 (2007).

7. $\mathrm{P}$ SINGH, R MEHTA, S AGARWAL, $\mathrm{P}$ MISHRA. Bacterial biofilm on the sinus mucosa of healthy subjects and patients with chronic rhinosinusitis (with or without nasal polyposis). J Laryngol Otol. 129:46-49 (2015).

8. J DLUGASZEWSKA, M LESZCZYNSKA, M LENKOWSKI, A TATARSKA, T PASTUSIAK, W SZYFTER. The pathophysiological role of bacterial biofilms in chronic sinusitis. Eur Arch Otorhinolaryngol. 273(8):1989-94. doi: 10.1007/s00405- 015-3650-5. Epub 2015 May 30. (2016).

9. M GEORGESCU, D VRINCEANU, L RADULESCU, M TUSALIU, C MARTU, C CURUTIU, MD HUSSIEN, V BUDU. Microbial biofilms and implantable hearing aids. Rom Biotechnol Lett. 22(4):12681-12686 (2017).

10. S LEE, AP LANE. Chronic rhinosinusitis as a multifactorial inflammatory disorder. Curr Infect Dis Rep. 13(2):159-168 (2011).

11. L MALAGUARNERA. Chitotriosidase: the yin and yang. Cell Mol Life Sci. 63:3018-3029 (2006)

12. MA ELMONEM, LP VAN DEN HEUVEL, EN LEVTCHENKO. Immunomodulatory Effects of Chitotriosidase Enzyme. Enzyme Res 2016:2682680 (2016).

13. S MUSUMECI. Interferon-gamma, tumor necrosis factoralpha, and lipopolysaccharide promote chitotriosidase gene expression in human macrophages. J Clin Lab Anal. 19(3):128-32 (2005).

14. RA CIOCAN, C DRUGAN, CD GHERMAN, CS CATANA, A CIOCAN, TC DRUGAN, SD BOLBOACA. Evaluation of chitotriosidase as a Marker of Inflammatory Status in Critical Limb Ischemia. Ann Clin Lab Sci. 6(47):713-719 (2017).

15. NA AKBAR, MA ZACHAREK. Vitamin D: immunomodulation of asthma, allergic rhinitis, and chronic rhinosinusitis. Curr Opin Otolaryngol Head Neck Surg. 19:224-228 (2011).

16. DL KAMEN, V TANGPRICHA. Vitamin D and molecular actions on the immune system: modulation of innate and autoimmunity. J Mol Med (Berl). 88(5):441450 (2010).

17. M GALLIENI, M COZZOLINO, G FALLABRINO, et al. Vitamin D: physiology and pathophysiology. Int J Artif Organs. 32:87-94 (2009).

18. HF DeLUCA, MT CANTORNA. Vitamin D: its role and uses in immunology. FASEB J. 15:2579-2585 (2001).

19. CJ HOCHSTIM, JY CHOI, D LOWE, R MASOOD, D RICE. Biofilm detection with Hematoxylin-Eosin staining. Arch Otolaryngol Head Neck Surg. 136 (5):453456 (2010).

20. G SRIDHARAN, AA SHANKAR. Toluidine blue: A review of its chemistry and clinical utility. J Oral Maxillofac Pathol. 16(2):251-255. doi: 10.4103/0973029X.99081. (2012).

21. CE HOLLAK, S VAN WEELY, MH VAN OERS, JM AERTS. Marked elevation of plasma chitotriosidase activity. A novel hallmark of Gaucher disease. J Clin Invest. 93:1288-92 (1994).

22. RG BOOT, GH RENKEMA, M VERHOEK, et al. The human chitotriosidase gene. Nature of inherited enzyme deficiency. J Biol Chem. 273:25680-5 (1998).

23. RE GLIKLICH, R METSON. The impact of chronic sinusitis in patients seeking otolaryngologic care. Otolaryngol Head Neck Surg. 113:104-109 (1995).

24. A KATO. Immunopathology of chronic rhinosinusitis. Allergol Int. 64:121-130 (2015).

25. CJ HOCHSTIM, R MASOOD, DH RICE. Biofilm and persistent inflammation in endoscopic sinus surgery. Otolaryngol Head Neck Surg. 143:697-698 (2010).

26. JH JUNG, HE CHA, IG KANG, ST KIM. Clinical characteristics of biofilms in patients with chronic rhinosinusitis: a prospective case-control study. Indian J Otolaryngol Head Neck Surg. 67(1):1-6 (2015).

27. AM HEKIERT, JM KOFONOW, L DOGHRAMJI, DW KENNEDY, AG CHIU, JN PALMER, JG LEID, NA COHEN. Biofilms correlate with TH1 inflammation in the sinonasal tissue of patients with chronic rhinosinusitis. Otolaryngol Head Neck Surg. 141(4):448-453. doi: 10.1016/j.otohns.2009.06.090. (2009)

28. X WANG, J DU, C ZHAO. Bacterial biofilms are associated with inflammatory cells infiltration and the innate immunity in chronic rhinosinusitis with or without nasal polyps. Inflammation. 37(3):871-9. doi: 10.1007/ s10753-013-9807-8. (2014)

29. V TROMBITAS, AA NAGY, D VLAD, A ILEA, S ALBU. Biofilms and nasal wound healing in postsurgical patients with chronic rhinosinusitis - A review of literature Romanian Journal of Rhinology. 5(20):203-208 (2015).

30. D SINGHAL, AJ PSALTIS, A FOREMAN, PJ WORMALD. The impact of biofilms on outcomes after endoscopic sinus surgery. Am J Rhinol Allergy. 24(3):169-74. doi: 10.2500/ajra.2010.24.3462. (2010). 
31. L VAN DUSSEN, JE HENDRIKS, JEM GROENER, RG BOOT, CE HOLLAK, JM AERTS. Value of plasma chitotriosidase to assess non-neuronopathic Gaucher disease severity and progression in the era of enzyme replacement therapy. J Inherit Metab Dis 37:991-1001 (2014).

32. SK PARK, HW CHO, KW HEO, DY HUR, HK LEE. Role of mammalian chitinase and chitotriosidase in nasal polyps. Otolaryngol Head Neck Surg. 141(4):462-466. doi: 10.1016/j.otohns.2009.06.013. (2009).

33. SK PARK, KW HEO, DY HUR, YI YANG. Chitinolytic activity in nasal polyps. Am J Rhinol Allergy. 25(1):1214. doi: 10.2500/ajra.2011.25.3555. (2011).

34. KW HEO, TY KIM, SK PARK, GB PARK, DY HUR, WY BAE. Nasal polyp chitinolytic activity associated with smoking or allergy. Int Forum Allergy Rhinol. 4:353356 (2014).

35. WM ABUZEID, NA AKBAR, MA ZACHAREK. Vitamin D and chronic rhinitis. Curr Opin Allergy Clin Immunol. 12(1):13-7 (2012).

36. PJ STOKES, J RIMMER. The relationship between serum vitamin $\mathrm{D}$ and chronic rhinosinusitis: A systematic review. Am J Rhinol. 30 (1):23-28. doi:10.2500/ajra. 2016.30.4267. (2016)

37. JK MULLIGAN, BS BLEIER, B O'CONNELL, RM MULLIGAN, C WAGNER, et al. Vitamin D(3) correlates inversely with systemic dendritic cell numbers and bone erosion in chronic rhinosinusitis with nasal polyps and allergic fungal rhinosinusitis. Clin Exp Immunol 164: 312-320. (2011)

38. JK MULLIGAN, W NAGEL, BP O'CONNELL, J WENTZEL, C ATKINSON, RJ SCHLOSSER. Cigarette smoke exposure is associated with vitamin D3 deficiencies in patients with chronic rhinosinusitis. J Allergy Clin Immunol. 134(2):342-349 (2014).

39. JK MULligAN, DR WHITE, EW WANG, SR SANSONI, H MOSES, RJ YAWN, et al. Vitamin D3 deficiency increases sinus mucosa dendritic cells in pediatric chronic rhinosinusitis with nasal polyps. Otolaryngol Head Neck Surg. 147:773-81 (2012).

40. RJ SCHLOSSER, ZM SOLER, GW SCHMEDES, K STORCK, JK MULLIGAN. Impact of vitamin D deficiency upon clinical presentation in nasal polyposis. Int Forum Allergy Rhinol. 4(3):196-199. doi: 10.1002/ alr.21274. Epub 2014 Jan 10. (2014).

41. LF WANG, CH LEE, CY CHIEN, JY CHEN, FY CHIANG, CF TAI. Serum 25-hydroxyvitamin D levels are lower in chronic rhinosinusitis with nasal polyposis and are correlated with disease severity in Taiwanese patients. Am J Rhinol Allergy. 27: e162-e165 (2013).

42. WW CAROLL, RJ SCHLOSSER, BP O'CONNELL, ZM SOLER, JK MULLIGAN. Vitamin D deficiency is associated with increased human sinoasal fibroblast proliferation in chronic rhinosinusitis with nasal polyps. Int Forum Allergy Rhinol. 6:605-610 (2016).

43. B ROSTKOWSKA-NADOLSKA, E SLIUPKASDYRDA, J POTYKA, D KUSMIERZ, M FRACZEK, et al. Vitamin D derivatives: calcitriol and tacalcitriol inhibits interleukin-6 and interleukin- 8 expression in human nasal polyp fibroblast cultures. Adv Med Sci. 55:86-92 (2010).

44. B ROSTKOWSKA-NADOLSKA, M FRACZEK, W GAWRON, M LATOCHA. Influence of vitamin $\mathrm{D}(3)$ analogues in combination with budesonid $\mathrm{R}$ on proliferation of nasal polyp fibroblasts. Acta Biochim Pol 56: 235-242 (2009).

45. B SULTAN, M RAMANATHAN Jr, J LEE, et al. Sinonasal epithelial cells synthesize active vitamin D, augmenting host innate immune function. Int Forum Allergy Rhinol. 3:26-30 (2013).

46. SC PARK, Y PARK, KS HAHM. The role of antimicrobial peptides in preventing multidrug-resistant bacterial infections and biofilm formation. Int J Mol Sci. 12:5971-5992. doi:10.3390/ijms 12095971. (2011). 